\title{
Video Game Experiential Marketing in Tourism: Designing for Experiences
}

\author{
Mattia Rainoldi ${ }^{1(\bowtie)}(\mathbb{D})$, Arne Van den Winckel ${ }^{1}$, Joanne $\mathrm{Yu}^{2}(\mathbb{D}$, \\ and Barbara Neuhofer ${ }^{1}$ (D) \\ ${ }^{1}$ Salzburg University of Applied Sciences, Salzburg, Austria \\ \{mattia.rainoldi, avandenwinckel. imte-m2018, barbara. \\ neuhofer\}@fh-salzburg.ac.at \\ 2 Modul University Vienna, Vienna, Austria \\ joanne.yu@modul.ac.at
}

\begin{abstract}
While film and television have a long tradition in tourism marketing, the potential of video games is overlooked. This study unlocks a novel era of marketing by investigating the interplay between experiential factors and ingame experiences, and how they may contribute to one's intention to visit ingame destinations. By taking Assassin's Creed Odyssey as the study context, game world dynamics, level of immersion, level of freedom, connection to characters, and sense of realism are identified as the five pillars that shape gaming experiences. Drawing upon experience design, this study lays the groundwork for emerging marketing opportunities using video games for tourism and contributes to the broader field of media-induced tourism literature.
\end{abstract}

Keywords: Video game-induced tourism $\cdot$ Experience design $\cdot$ Media-related tourism $\cdot$ Experiential marketing

\section{Introduction}

With the advent of experience economy [1], marketers have been attempting to engage potential tourists in pre-trip stages by designing experiential marketing stimuli [2] through various mediums such as television programmes, films [3, 4], and emergingly, video games [5]. Commonly known as media-related tourism, the central idea is that destination image and future visitation are interwoven with each other due to the influence of media [6]. Yet, the focus of existing studies is rather limited to the scope of film and television [4, 5, 7]. Most recently, the application of video games has been adopted to amplify the level of freedom, emotion, immersion, and interactivity [8]. Video games are novel in that they give gamers an opportunity to freely roam in a virtual world [7] and stroll around like tourists. Similar to virtual tours [9], gamers, defined as potential tourists, can find out experiential marketing messages of a destination (in-game location) and evaluate them before their actual visit [10]. That is, experiential marketing is not about promoting a product or service, but allowing potential tourists to see, feel, and have a glimpse of live experiences [11]. Because of 
the immersive nature of in-game experiences, gamers often feel deeply connected to the main characters and the virtual world they live in [12]. Hence, gaming can be considered as an experiential vehicle that engages potential tourists, generates positive image, and improves communication [7].

However, the potential of video games is still an under-researched area [5]. Using gaming for promotion has neither been embraced as an experiential marketing tool in the tourism industry, nor has it reached the stage of maturity development $[6,7]$. Since gamers are still a relatively small market in tourism, it remains unfeasible for game developers to design tourism-specific games exclusively for this group [13]. Additionally, the fact that most popular games are violent by nature (e.g., first-person shooting) [14] makes it difficult to integrate tourists' needs (e.g., memorabilia and inner growth) and gamers' desires (e.g., aggressive feelings and behaviours) [13]. Other scholars argue that one potential factor hindering the development of video gameinduced tourism is because the design of experiences is not engaging [6] because game developers may be unaware of tourists' needs [13].

Although recent literature has initiated a call for video game-induced tourism, there is a strong focus on tourist motivations and destination image $[6,7,12]$, whereas the fundamental concept, experience, is overlooked. Thus, this research aims to exploratorily expose experiential factors that are influential to in-game experiences, and how they may contribute to gamers' intention to visit in-game locations. Intrigued by the ambiguity of video game-induced tourism, this study goes beyond the traditional marketing discipline by borrowing the lens of experience design. By outlining the main experiential factors that inspire gamers to visit certain in-game locations, this paper lays the groundwork for new experiential marketing opportunities through video games and contributes to the broader field of media-induced tourism literature.

\section{Literature Review}

\subsection{Video Game and Video Game-Induced Tourism}

Increasingly, video games have received attention in education, health, and other nongaming businesses [13] such as tourism. In tourism marketing [6], video games stand out from all types of media as the engagement in the gaming experience often extends over $30 \mathrm{~h}$ [15]. Video games are based on gamification, referring to the practice of applying gaming methods to engage and increase the overall experience in a nongaming context [16]. However, current interest in gamified experiences seem to be limited to mobile games (e.g., Pokémon Go as a marketing tool) [6], whereas video games in tourism marketing still receive little attention [5, 7].

The intangible nature of tourist experiences intensifies a need for marketers to tell stories [17] and craft immersive and engaging experiences [18]. Video games are valuable in that they allow potential tourists to pre-experience the reproduction of a destination [6]. A recent study discovered that emotional attachment, historic experiences, adventurous journeys, scenic views, and the hero feeling are some of the key drivers for young gamers to visit a destination [12]. Other motivations include, freedom 
in a virtual world, excitement [10], role-playing, character development, immersion, escapism [19], and social interaction [13], among many others.

In tourism marketing, in addition to hedonic consumption, video games provide information of a location in real-time [5]. Since locations in video games are often an ideal or apocalyptic representation of a real-life environment in accompanied by fantasy [20], video games could be useful for pre-experiencing points of interests and promoting tourists' attractions to gamers [13]. By doing so, video games may encourage gamers to visit the location portrayed in the game. While video gameinduced tourism is considered as one of the most effective approaches to leave a lasting impression on gamers due to the high level of immersion [7], marketers should be aware that tourists might crave for experiences exactly as they are depicted in games [5]. Thus, given the infancy of gaming in tourism marketing, there is an urgent need for game developers to harmoniously integrate the desires of tourists and gamers [7, 13]. Yet, insufficient understanding towards in-game experiences and gamers as an emerging market [13] often constrains the development of video game-induced tourism.

\subsection{Bridging Experience Design to Video Game-Induced Tourism}

With a growing interest in video games which resemble an interactive and socialising environment [21], challenges emerge because gamers expect more personalised and experiential forms of travel through games rather than a simple form of entertainment [13]. Since experiential marketing heavily relies on imagery processing, visualisation, multi-sensory experiences, and symbolic features of a destination serve as the key factors influencing the effectiveness of marketing messages [2].

Similar to virtual reality tours [22], video games allow gamers to explore destinations, but at a higher level of interactivity and immersion [23]. Drawing upon the four realms of experiences (i.e., entertainment, education, escape, and esthetic) [24], gamers move from passive absorption to active participation in gaming experiences. In such a highly engaging environment, gamers are offered a sense of escapism, which often occurs outside one's daily life [19]. Apart from the missing link between experience design and video game-induced tourism [6], what is more urgent is that gamers have gradually entered the next-phase of experiences where personal development, self-actualisation, and positive emotions are valued [18, 25, 26]. Yet, those experiences do not happen occasionally. In video games, gamers are called to adventure to explore in-game locations [12]. They leave their ordinary life and step into a liminal space by immersing themselves in the extraordinary virtual environment. Gamers encounter challenges and rewards, which act as a source of motivation for them to have a goal throughout the process. Potentially, they acquire new knowledge and skills upon return.

In line with using the Hero's Journey as a design thinking tool [27], tourism marketers and game designers can optimise the storyline and the flow of the journey [28]. By examining gamers' actions, emotions, and thoughts, potential design opportunities can be identified. What is common between experience design and video games is intentionality [6, 29]. Experience design utilises a human-centered approach by intentionally creating new offerings [30]. Yet, due to the infancy of applying video games in tourism, their current performance as marketing tool may not necessarily 
exceed that of other mediums (e.g., film) [7]. It is thus critical to further explore ingame experiential marketing elements and improve the design of video games to ultimately lead to positive outcomes (e.g., visit intention).

\section{Methodology}

\subsection{Study Context: Assassin's Creed Odyssey}

Assassin's Creed Odyssey, an action role-playing video game set in the years 431-422 BC, was selected as the study context. The story centres on the Peloponnesian War, an ancient Greek war, between Athens and Sparta. Gamers are allowed to choose a main character and can develop relationships with non-player characters (NPCs). Within the game, gamers can virtually explore the culture, history, and beauty of the ancient Greek world. The 'I was there when that happened' experience is what differentiates Assassin's Creed Odyssey from other games [23]. Gamers can take screenshots and share them with the game community, just like how tourists often share travel photos on social media and/or with friends. Assassin's Creed Odyssey is designed in a nonviolent concept, which is what makes it suitable in video game-induced tourism [7].

\subsection{Sample and Sampling Procedures}

A qualitative in-depth interview approach was used in this exploratory study. A purposive sampling technique was applied to invite people experienced in Assassin's Creed Odyssey. Participants with considerable experience playing the game were recruited through social media channels, gamer forums, and the researchers' personal contacts in the game industry. A total of 12 male participants was interviewed, ranging between 20 to 37 years old. On average, participants spent about eight hours on video games per week and have been playing for seven years. More than half of them $(58 \%)$ have travelled to Greece. This sample size is also similar to other studies analysing underexplored topics in tourism [32-34].

Questions were constructed based on literature in video game-/film-induced tourism $[5,7,31]$ and experience design $[16,18]$. The semi-structured interviews centered on a) emotional experiences, b) atmosphere, culture, history, and nature of in-game locations, c) perceptions towards the plot, d) personal connection with the character, e) perceptions towards in-game functions, f) resembling of the real-life setting, as well as g) intention to visit in-game locations. Interviews were conducted in English via online meeting platforms from April to June 2020. Each interview lasted about $30 \mathrm{~min}$. All interviews were manually transcribed. Due to the infancy of video game-induced tourism, an inductive thematic analysis [35] was adopted to uncover emerging patterns and re-occurring phenomena. Five main themes with 30 experiential sub-themes were identified, which overall, enhance participants' intention to visit the destination. 


\section{Results and Discussion}

This study conceptualises five main experiential marketing factors that are influential to in-game experiences and one's intention to visit Greece, namely a) game world dynamics, b) level of immersion, c) level of freedom, d) connection to the characters being 'the hero', and e) sense of realism (Fig. 1). A detailed discussion of each dimension and its sub-themes follows.

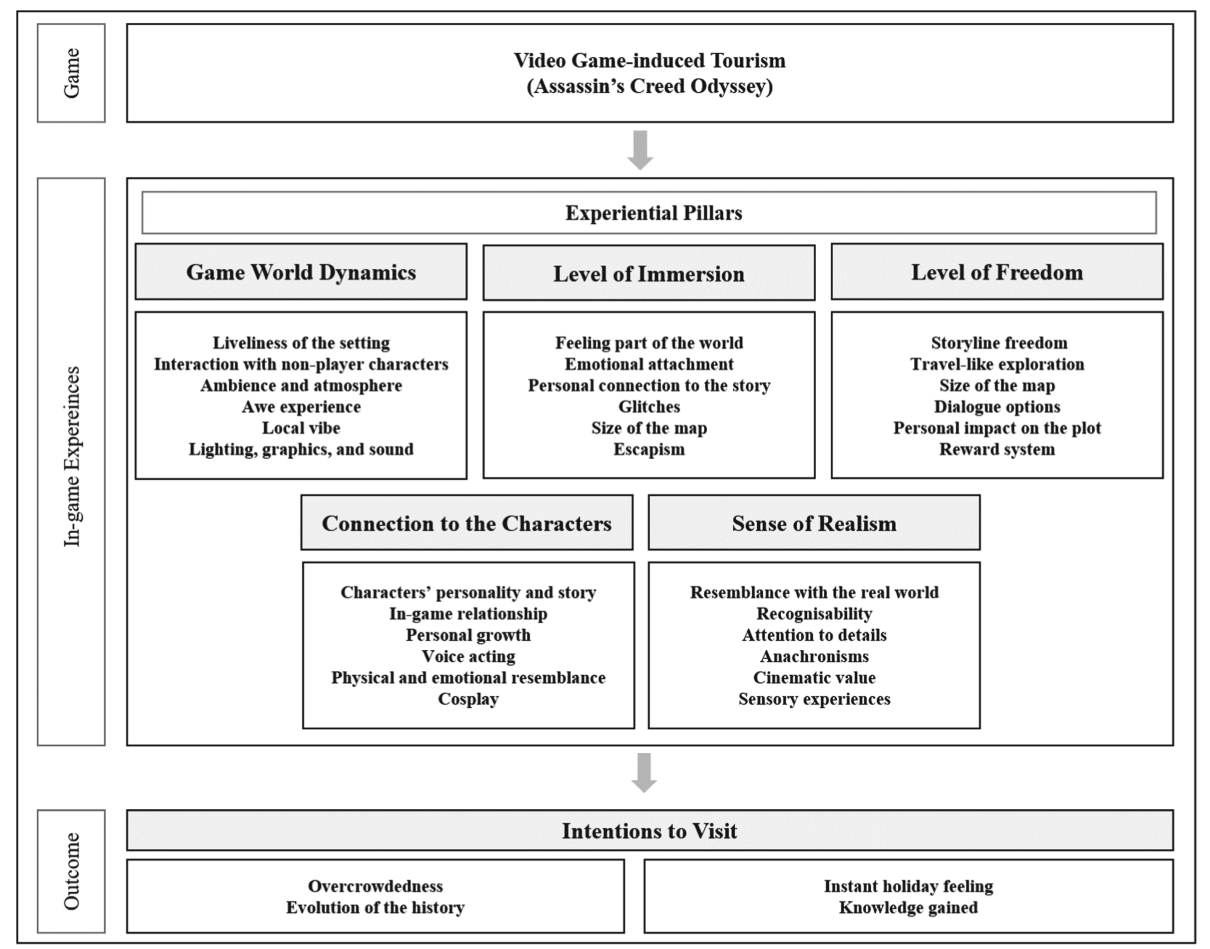

Fig. 1. Experiential marketing pillars of video game-induced tourism.

\subsection{Game World Dynamics}

The dynamics of the in-game world is found to be one of the most important factors to players. An exemplary quote is, 'The cities were very alive with many people walking around and doing their daily things, [...] like I was walking through the cities myself' (11). This corresponds to the characteristics of tourists, who appear to share similar behaviours in the game as they would behave in actual travel [20]. Other participants highlighted the role of NPCs in enhancing the feeling of realness (e.g., '[The NPCs] made the place feel so alive' (10)). The way the participant interacted with the local people reinforced the idea of being gamers (e.g., '[The NPC] can talk to you, it improves the interaction and gives a good impression about the daily life' (3)). As 
video games often offer a higher level of interactivity [23], interactions with NPCs serve as key drivers in making the experiences more active and engaging [36].

Meanwhile, the ambience and atmosphere of the virtual environment left most of players in awe, characterised as one of the most intense and positive emotional experiences. One participant stated, '[I am] really impressed [...], especially the landscapes, the building, historical accuracy of the building, [...] I was just in awe' (5). In fact, this phenomenon can be explained from the power of natural scenery. Scholars have underpinned the effectiveness of vast geological landscape as aweinducing stimuli [37], having the potentials to foster personal growth [38]. Also, many participants mentioned the uniqueness of local vibe. An example is, 'You could go to the other side of the map and you would feel a totally different vibe [...] so dynamic and alive' (1). The vibe was not just made up by physical locations, but co-created with the locals (e.g., 'When you walk through these little villages [...], you see people buy stuff and talk to each other. Yes, it's a really dynamic experience' (4)). Existing literature have explained the interplay between objects and players in video games from the lens of affordance theory [39]. These findings affirmed that the affordance in video games can have an indirect impact on the destination choice of participants.

\subsection{Level of Immersion}

Immersion is another factor that influences the destination choice of gamers. Several participants stated that they felt part of the world and that they were really walking through ancient Greece (e.g., 'I was immersed automatically [...] you are more focused on learning new things, and you run to the different point' (2)). Some participants compared the level of immersion between watching a film and playing a video game (e.g., 'Video games are always more immersive than movies [...] because you can actually control the characters and have an actual effect on the story' (10)). Supported by the study of Sajid [12], video games could possibly bring more emotional attachment for the gamers than a film.

However, to prevent boredom in the large open world (e.g., 'Sometimes walking through the endless nature or forests could be a bit boring when there is nothing to do' (11)), the participants proposed that sound effects and background music are important to keep gamers immersed (e.g., 'You can let the exploration music play a little more [...] because it offsets some of the really quiet moments while exploring' (5)). Moreover, certain graphical glitches can result in a loss of immersion as it does not correspond with real-life settings. The participant mentioned, 'Only maybe the glitches sometimes [...] This took away the immersion in the game sometimes' (10).

Other participants mentioned that playing video games serves as a form of escapism from the real world as they often lose track of time (e.g., 'It helps to manage stress and getting away from all the negative news nowadays, because it takes a lot of your time, (8)). In fact, games that are similarly to real-life tourism [6] can offer gamers a way to escape from daily tasks and routine [19]. Likewise, due to the captivating nature of the story, several gamers felt emotionally connected to the story of characters. One participant stated, 'Some of the characters were very deep and had a bigger meaning to the main character's life [...] I could really emotionally connected and immersed' (6). 


\subsection{Level of Freedom}

The third experiential pillar is the extent of freedom which players are offered. An example was, 'You could actually keep on going and going. You can follow the main story [...], but you can also choose to discover all the secret islands and the viewpoints' (4). Some gamers emphasised that the freedom to explore the game world resembled travelling in real life, such as 'You could travel freely and if I would go to Greece, I would want to do island hopping, as I did in the game' (2). One of the main features that enhanced the feeling of freedom is the size of the map in the game that allowed one to keep exploring new things. One participant stated, 'You could literally walk for hours. I've spent around $70 \mathrm{~h}$ and I still haven't explored everything yet [...] it gives you a sense of freedom when exploring the world' (5).

Another feature that conveyed a sense of freedom was the open dialogue function. Through this feature, gamers could influence the way the story progressed with their own decisions. For instance, 'You can answer the tricky questions and intentionally select the wrong answers to see how far they can go' (8). Also, the fact that gamers were empowered to have an impact on the plot heightens the sense of freedom (e.g., 'It was like finding your own story and the different plots that came later. [...] I really liked the multiple storylines and how you could go through them however you wanted' (1)). The in-game reward system (e.g., treasures and bonus points) was an additional factor influencing the feeling of freedom. An example was, "[Side missions] were something I tried to do a lot, just see the side quests and side stories [...] also just for gameplay reasons you get a higher level, you get some rewards for doing them' (12).

The findings suggest that open world games can better serve as a resemblance of real tourism settings. Yet, game designers should be aware of flow experiences in the concept of gamification [16]. An optimal flow state suggests that an individual is capable of solving the presented challenges [28], which is thus crucial in influencing the sense of freedom, engagement, and immersion [18].

\subsection{Connection to the Characters - Being 'the Hero'}

Several participants indicated that they felt personally connected to the main character in terms of his/her background story and ideas. Described by one participant, 'As I played [with Kassandra], I really felt connected to the character. I was actually really touched by some of the things that happened to the character and the characters around her' (7). This notion of building in-game relationships, as also described by Teng [40], affected the gamers in a way they experienced the sense of escapism and temporarily residing in an alternative world. Going beyond the emotional attachment, other participants stated that they have grown together with the character. One participant stated, 'I liked how you were able to grow together with the main character and feeling what they were feeling at certain moments' (12). Hence, some participants would like to even follow the footsteps of the character in real life by visiting the ingame locations. For instance, 'I can follow my footsteps in the game. I would really consider doing this [in reality] to see how everything is compared to in the game' (1).

Similarly, few participants shared that they would love to dress up and 'being' in that character for a day in real life (e.g., 'It would be interesting to dress up and have 
some certain designated street for that. Let's say you collect some gamers around the world and let them dress up as an Assassin' (8)). This suggests that one of the motivational factors for visiting in-game locations is to walk in the shoes of a character [12]. Interestingly, the findings also reveal voice acting as a critical element in enhancing the connection. For instance, one participant stated, 'I played as Kassandra [...] The voice acting made me feel a connection with her' (6). Consistent with the context of film tourism, the personality of a character in the film, the casting choices and the involvement of celebrities were found to be some of the key factors motivating one's intention to travel [41]. Presumably, the involvement of well-known historical figures in video games (e.g., Hippocrates) could replace the celebrities often found in films.

\subsection{Sense of Realism}

As for the sense of realism, participants compared in-game locations with what they have already seen in real life (e.g., 'I went to Kos in real life [...] The first thing, when you come to Kos in the game, you immediately find out it is all about wine and there are huge vineyards' (3)). Interestingly, the recognisability of in-game locations also contributes to the level of realism (e.g., 'You could recognise some of the landmarks and it was amazing to find all these things, wander around Greece just from behind your desk actually' (1)). Also, several participants highlighted attentions to details in terms of the in-game design (e.g., 'The way it all was shaped, the different islands, something typical about Greece, but also the way they made the lighting, the sculptures, the Greek architecture, the mountains you had to travel' (4)). These findings correspond to the significance of scenery and landscapes mentioned by Sajid [12] as the main factors for gamers to travel to a destination.

However, there were noticeable anachronisms in the games since some of the elements were not historically accurate, which may lower the level of realism (e.g., 'There was a woman, she had a lot of power. I don't think in ancient Greece, females had that kind of power' (7)). Yet, such reflection also depends on the experiences and knowledge of gamers. Other participants emphasised the cinematic value of the game, especially the graphics and sound effects, and how it resembles a movie. One interviewee stated, 'If you have a good sound effect, you will be more engaged.' (8). Another participant described, 'The impressive graphics of the game had definitely an impact [...] The lighting and the colours were just perfect and resembled the real world' (10). However, some of the participants added that games would never replace the actual experience of visiting a destination despite the richness of sensory experiences (e.g., 'I think if to stimulate this gaming experience in relation to holidays, a game can never replace the actual experience in the game' (6)).

\subsection{General Perceptions and Intention to Visit Greece}

Overall, the destination image of Greece has changed slightly as a result of playing the game. It is usually a combination of the previous knowledge or image about the destination and what gamers have learned during the game. Certainly, few participants held an opposite viewpoint. For example, gamers can be alone at some of the sceneries 
and landmarks, as opposed to real life where overcrowdedness might be expected. The participant stated, 'You're not going alone to those kind of tourist locations, you're always surrounded with a lot of people. And playing the game, I must admit that I didn't see a lot of unrecognisable stuff' (7). Likewise, participants shared their concerns on the landmarks being destroyed over time as the game was set more than two thousand years ago (e.g., 'You have the ancient temples and so on [in the game], but I don't know if they still exist in Greece. So, I don't know if I could go there' (11)).

Yet, most of the participants expressed their interest to visit Greece and witness the landmarks in person. For instance, 'The island of Crete is something I have always wanted to see but now I really want to go there because I have seen the different landmarks there and I really want to see this actually (2)'. Participants also stated that seeing and exploring certain landmarks in the video game has increased the willingness to pay for an entrance fee for some of the attractions from the game. An exemplary quote is, 'It's genuinely nice to see the landscapes and for me it gives like a stimulation to go on a holiday. This game actually makes me think to go on holiday and especially the landscapes could convince me to go there' (3).

Finally, it is important to note that although the identified pillars, per se, may not directly motivate one's visitation, experiential marketing does play an important role in facilitating and influencing gamers' subsequent actions. Altogether, the experiential factors discussed above co-shape gamers' willingness to visit some of the in-game locations in real life.

\section{Conclusions}

\section{$5.1 \quad$ Theoretical Contributions}

Through an exploratory investigation, this research deepens our understanding towards how in-game experiences shape potential tourists' perceptions and visitations, and vice versa, based on the case of Assassin's Creed Odyssey. By uncovering key experiential marketing factors that are compelling to in-game experiences and intention to visit ingame locations, this study contributes to novel ways of understanding video gameinduced tourism by bringing knowledge from the lens of experience design. Different from previous studies heavily focusing on the end factors such as tourist arrivals and motivations [3, 4, 10], this research specifically looks into the what and how experiences can be constructed. Overall, to motivate gamers to visit in-game locations, the findings shed light on the dynamics of game world, immersion, freedom, connection to the characters, and sense of realism as some of the dimensions that merit attention. Rooted in the field of experience design, an interconnection between the identified factors has been showcased. Their interwoven relationship spotlights potential challenges and opportunities of video game-driven tourism. This study is thus valuable in that it expands the status quo of in-game marketing and adds empirical knowledge to experiential marketing practices and the broader field of media-induced tourism literature. 


\subsection{Practical Implications}

By outlining the main experiential marketing layers, this study provides guidelines to optimise in-game experiences from the lens of experience design, which ultimately may drive actual travel. First, to improve a sense of realism when using video games for experiential marketing practices, the findings highlight attention to details as design essentials. Yet, designers and marketers need to be cautious with potential glitches in the game that could diminish the level of immersion. Meanwhile, this study underlines the dynamics of sound effects and background music, which appear to be overlooked by game developers. Due to the size of the virtual environment, not every location was filled with quests. Music, however, can counterbalance the feeling of boredom and enhance the level of freedom while gamers are wandering around to keep the flow and emotions. Additionally, game developers are encouraged to collaborate with destination marketers to strengthen the authenticity of tourist experiences. Seeing the importance of emotional/physical connections, marketers may consider role-playing as an offer to tourist players on site. By incorporating storytelling in experiential marketing, for example, tourism businesses can prepare costumes and allow gamers to dress up like in-game characters to specifically tailor their needs. Finally, it is important to note that the non-violent nature of the video game seems to perform better than the violent ones. In this study, gamers could learn the history of ancient Greece without relating to any negative aspect. Yet, in another study investigating the violent context [7], gamers were more likely to think about grim events happening in this game (e.g., shooting violence). Destination marketers are thus suggested to consider the intended experiential marketing messages. For example, violent video games, which is more a mainstream in the video game industry, could have more potential in marketing warrelated destinations and adventurous activities.

\subsection{Limitations and Recommendations}

This research is not without limitations. First, transferability of the findings is in question due to the limited respondence to the interview invitations. This might be resulted from the specific criteria of being a gamer for only one particular video game. However, since the sample size is similar to recent research focusing on underexplored topics $[33,34]$ and has reached data saturation, the exploratory nature of this study still provides valuable insights on underlying experiential factors contributing to the context of video game-induced tourism. Future research is recommended to investigate how the identified experience pillars in different types of media-related tourism may shape travel experiences. Likewise, the choice of using one specific game limited the type of gamers that participated in the study. Because the genre of Assassin's Creed Odyssey is action-adventure and role-playing-oriented, the majority of the participants was male. Scholars are suggested to replicate the study's methods and compare how experiences differ in different genres of video games. Also, Assassin's Creed Odyssey is based in Greece, which is already a well-known touristic destination. Researchers are encouraged to investigate the effect of video games in less popular destinations. Finally, from an experience design perspective, it is important to explore the long-term impact of ingame experiences. Because immersive and extraordinary experiences are long-lasting 
by nature [18], longitudinal research is recommended in order to go beyond the immediate effect of gaming experiences (e.g., visitations) and move into the wider context of its impact on gamers' lives (e.g., personal development).

\section{References}

1. Pine BJ, Gilmore JH (2011) The experience economy. Harvard Business Press, Boston

2. Le D, Scott N, Lohmann G (2019) Applying experiential marketing in selling tourism dreams. J Travel Tour Mark 36:220-235

3. Kim S, Kim S, King B (2019) Nostalgia film tourism and its potential for destination development. J Travel Tour Mark 36:236-252

4. Kim S, Kim S (2018) Perceived values of TV drama, audience involvement, and behavioral intention in film tourism. J Travel Tour Mark 35:259-272

5. Ramirez-Moreno C, Leorke D (2021) Promoting Yokosuka through videogame tourism: the shenmue sacred spot guide map. In: Games and play in the creative, smart and ecological city, pp 38-63

6. Dubois L-E, Gibbs C (2018) Video game-induced tourism: a new frontier for destination marketers. Tour Rev 73:186-198

7. Dubois L-E, Griffin T, Gibbs C et al (2021) The impact of video games on destination image. Curr Issue Tour 24:554-566

8. Flavián C, Ibáñez-Sánchez S, Orús C (2019) The impact of virtual, augmented and mixed reality technologies on the customer experience. J Bus Res 100:547-560

9. Cho YH, Wang Y, Fesenmaier DR (2002) Searching for experiences: the web-based virtual tour in tourism marketing. J Travel Tour Mark 12:1-17

10. Xu F, Tian F, Buhalis D et al (2013) Marketing tourism via electronic games: understanding the motivation of tourist players. In: 5th International conference on games and virtual worlds for serious applications, pp 1-8

11. Rather RA (2020) Customer experience and engagement in tourism destinations: the experiential marketing perspective. J Travel Tour Mark 37:15-32

12. Sajid F (2018) Video gaming a new face of inducement tourism: main attractors for juvenile gamers. Int J Soc Stud 4:52-56

13. Xu F, Tian F, Buhalis D et al (2016) Tourists as mobile gamers: gamification for tourism marketing. J Travel Tour Mark 33:1124-1142

14. Hartmann T, Vorderer P (2010) It's okay to shoot a character: moral disengagement in violent video games. J Commun 60:94-119

15. Snow B (2011) Why most people don't finish video games. http://edition.cnn.com/2011/ TECH/gaming.gadgets/08/17/finishing.videogames.snow/. Accessed 11 Apr 2021

16. Egger R, Bulencea P (2015) Gamification in tourism: designing memorable experiences. BoD-books on demand, Norderstedt, Germany

17. Yu J, Egger R (2021) Color and engagement in touristic Instagram pictures: a machine learning approach. Ann Tour Res 89:103204

18. Neuhofer B, Celuch K, To TL (2020) Experience design and the dimensions of transformative festival experiences. Int J Contemp Hosp Manag 32:2881-2901

19. Tychsen A, Hitchens M, Brolund T (2008) Motivations for play in computer role-playing games. In: Proceedings of the 2008 conference on future play research, play, share, pp 57-64

20. Salmond M, Salmond J (2016) The gamer as tourist: the simulated environments and impossible geographies of videogames. In: Tourism and the creative industries: theories, policies and practice, pp 151-163 
21. Howley D (2020) The world is turning to video games amid coronavirus outbreak. https:// finance.yahoo.com/news/coronavirus-world-turning-to-video-games-150704969.html

22. Beck J, Rainoldi M, Egger R (2019) Virtual reality in tourism: a state-of-the-art review. Tour Rev 74:586-612

23. Politopoulos A, Mol AAA, Boom KHJ et al (2019) "History is our playground": action and authenticity in assassin's creed: Odyssey. Adv Archaeol Pract 7:317-323

24. Song HJ, Lee C-K, Park JA et al (2015) The influence of tourist experience on perceived value and satisfaction with temple stays: the experience economy theory. J Travel Tour Mark 32:401-415

25. Gaggioli A (2016) Transformative experience design. Sciendo migration

26. Kirillova K, Lehto X, Cai L (2017) Tourism and existential transformation: an empirical investigation. J Travel Res 56:638-650

27. Allison ST, Goethals GR, Marrinan AR et al (2019) The metamorphosis of the hero: principles, processes, and purpose. Front Psychol 10:606

28. Seligman MEP, Csikszentmihalyi M (2014) Positive psychology: an introduction. In: Csikszentmihalyi M (ed) Flow and the foundations of positive psychology. Springer, Dordrecht, pp 279-298. https://doi.org/10.1007/978-94-017-9088-8_18

29. Tussyadiah IP (2014) Toward a theoretical foundation for experience design in tourism. J Travel Res 53:543-564

30. Finsterwalder J, Kuppelwieser VG (2020) Intentionality and transformative services: wellbeing co-creation and spill-over effects. J Retail Consum Serv 52:101922

31. Özdemir G, Adan Ö (2014) Film tourism triangulation of destinations. Procedia Soc Behav Sci 148:625-633

32. Aro K, Suomi K, Saraniemi S (2018) Antecedents and consequences of destination brand love - a case study from Finnish Lapland. Tour Manag 67:71-81

33. Chia KW, Liao YM (2021) An exploratory study of factors influencing Chinese outbound medical tourism. J China Tour Res 17(3):376-394

34. Seow D, Brown L (2018) The solo female Asian tourist. Curr Issue Tour 21:1187-1206

35. Braun V, Clarke V (2006) Using thematic analysis in psychology. Qual Res Psychol 3:77101

36. Roth C, Koenitz H (2016) Evaluating the user experience of interactive digital narrative. In: Proceedings of the 1st international workshop on multimedia alternate realities, pp 31-36

37. Pearce J, Strickland-Munro J, Moore SA (2017) What fosters awe-inspiring experiences in nature-based tourism destinations? J Sustain Tour 25:362-378

38. Pritchard A, Richardson M, Sheffield D, McEwan K (2019) The relationship between nature connectedness and eudaimonic well-being: a meta-analysis. J Happiness Stud 21(3):11451167. https://doi.org/10.1007/s10902-019-00118-6

39. Sjöblom M, Törhönen M, Hamari J et al (2019) The ingredients of Twitch streaming: affordances of game streams. Comput Hum Behav 92:20-28

40. Teng CI (2018) Managing gamer relationships to enhance online gamer loyalty: the perspectives of social capital theory and self-perception theory. Comput Hum Behav 79:5967

41. Macionis N (2004) Understanding the film-induced tourist. In: International tourism and media conference proceedings, vol 24, pp 86-97 
Open Access This chapter is licensed under the terms of the Creative Commons Attribution 4.0 International License (http://creativecommons.org/licenses/by/4.0/), which permits use, sharing, adaptation, distribution and reproduction in any medium or format, as long as you give appropriate credit to the original author(s) and the source, provide a link to the Creative Commons license and indicate if changes were made.

The images or other third party material in this chapter are included in the chapter's Creative Commons license, unless indicated otherwise in a credit line to the material. If material is not included in the chapter's Creative Commons license and your intended use is not permitted by statutory regulation or exceeds the permitted use, you will need to obtain permission directly from the copyright holder.

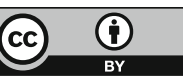

